\title{
Climate controls over the net carbon uptake period and amplitude of net ecosystem production in temperate and boreal ecosystems
}

\author{
Authors: Zheng Fua, Paul C. Stoy, Yiqi Luod, Jiquan Chen, \\ Jian Sun, Leonardo Montagnani, Georg Wohlfahrt, \\ Abdullah F. Rahman, Serge Rambal, Christian Bernhofer, \\ Jinsong Wang, Gabriela Shirkey, and Shuli Niu
}

NOTICE: this is the author's version of a work that was accepted for publication in Agricultural and Forest Meteorology Changes resulting from the publishing process, such as peer review, editing, corrections, structural formatting, and other quality control mechanisms may not be reflected in this document. Changes may have been made to this work since it was submitted for publication. A definitive version was subsequently published in Agricultural and Forest Meteorology, VOL\# 243, (September 15, 2017). DOI\# 10.1016/..agrformet.2017.05.009

Fu, Zheng, Paul C. Stoy, Yiqi Luo, Jiquan Chen, Jian Sun, Leonardo Montagnani, Georg Wohlfahrt, Abdullah F. Rahman, Serge Rambal, Christian Bernhofer, Jinsong Wang, Gabriela Shirkey, and Shuli Niu. "Climate controls over the net carbon uptake period and amplitude of net ecosystem production in temperate and boreal ecosystems." Agricultural and Forest Meteorology 243 (September 15, 2017): 9-18. DOI: 10.1016/j.agrformet.2017.05.009.

Made available through Montana State University's ScholarWorks scholarworks. montana.edu 


\title{
Climate controls over the net carbon uptake period and amplitude of net ecosystem production in temperate and boreal ecosystems
}

\author{
Zheng Fu ${ }^{\mathrm{a}, \mathrm{b}, \mathrm{c}}$, Paul C. Stoy ${ }^{\mathrm{c}}$, Yiqi Luo ${ }^{\mathrm{d}, \mathrm{e}}$, Jiquan $\mathrm{Chen}^{\mathrm{f}}$, Jian Sun ${ }^{\mathrm{a}}$, Leonardo Montagnani ${ }^{\mathrm{g}, \mathrm{h}}$, \\ Georg Wohlfahrt ${ }^{\mathrm{i}}$, Abdullah F. Rahman ${ }^{\mathrm{j}}$, Serge Rambal ${ }^{\mathrm{k}, 1}$, Christian Bernhofer ${ }^{\mathrm{m}}$, Jinsong Wang ${ }^{\mathrm{a}}$, \\ Gabriela Shirkey ${ }^{\mathrm{f}}$, Shuli Niu ${ }^{\mathrm{a}, \mathrm{b}, *}$

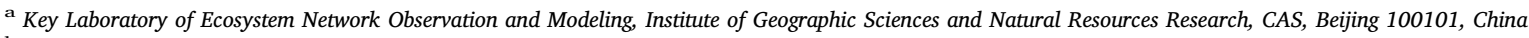 \\ b University of Chinese Academy of Sciences, No. 19A Yuquan Road, Beijing, 100049, China \\ ${ }^{c}$ Department of Land Resources and Environmental Sciences, Montana State University, Bozeman, MT 59717, USA \\ d Department of Earth System Science, Tsinghua University, Beijing 100084, China \\ e Department of Microbiology and Plant Biology, University of Oklahoma, Norman, OK 73019, USA \\ ${ }^{\mathrm{f}}$ Department of Geography, Environment, and Spatial Sciences and Center for Global Change and Earth Observations, Michigan State University, East Lansing, MI 48824, \\ USA \\ ${ }^{g}$ Forest Services of Autonomous Province of Bolzano, via Bolzano 6, 39100, Italy \\ ${ }^{\text {h }}$ Faculty of Science and Technology, Free University of Bolzano,Piazza Università 5, 39100, Bolzano, Italy \\ i Institute of Ecology, University of Innsbruck, Innsbruck, Austria \\ ${ }^{j}$ Coastal Studies Lab, University of Texas Rio Grande Valley, San Padre Island, TX 78597, USA \\ k CEFE UMR 5175, CNRS - Université de Montpellier - Université Paul-Valéry Montpellier - EPHE, F-34293, Montpellier Cedex 5, France \\ ${ }^{1}$ Universidade Federal de Lavras, Departamento de Biologia, CP 3037, CEP 37200000, Lavras, MG, Brazil \\ m Institute of Hydrology and Meteorology, Chair of Meteorology, Technische Universität Dresden, 01062 Dresden, Germany
}

\begin{abstract}
A B S T R A C T
The seasonal and interannual variability of the terrestrial carbon cycle is regulated by the interactions of climate and ecosystem function. However, the key factors and processes determining the interannual variability of net ecosystem productivity (NEP) in different biomes are far from clear. Here, we quantified yearly anomalies of

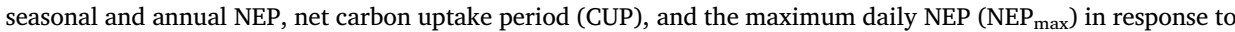
climatic variables in 24 deciduous broadleaf forest (DBF), evergreen forest (EF), and grassland (GRA) ecosystems that include at least eight years of eddy covariance observations. Over the 228 site-years studied, interannual variations in NEP were mostly explained by anomalies of CUP and NEP max. CUP was determined by spring and autumn net carbon uptake phenology, which were sensitive to annual meteorological variability. Warmer spring temperatures led to an earlier start of net carbon uptake activity and higher spring and annual NEP values in DBF and $\mathrm{EF}$, while warmer autumn temperatures in DBF, higher autumn radiation in EF, and more summer and autumn precipitation in GRA resulted in a later ending date of net carbon uptake and associated higher autumn and annual NEP. Anomalies in $\mathrm{NEP}_{\max } \mathrm{s}$ were determined by summer precipitation in DBF and GRA, and explained more than $50 \%$ of variation in summer NEP anomalies for all the three biomes. Results demonstrate the role of meteorological variability in controlling CUP and NEP ${ }_{\max }$, which in turn help describe the seasonal and interannual variability of NEP.
\end{abstract}

\section{Introduction}

Climate controls the terrestrial carbon cycle by regulating plant physiological processes, including phenology. Climate thus determines both ecosystem carbon uptake capacity as well as the length of the carbon uptake period, which are important determinants of ecosystem carbon sequestration (Falge et al., 2002b; Gu et al., 2009; Xia et al., 2015; Zhou et al., 2016). It is far from clear how climatic or meteorological changes impact net ecosystem production (NEP) by changing carbon uptake phenology and physiology, given that models are largely unable to simulate the interaction between climate and ecosystem carbon dynamics to date (IPCC, 2013). 
Previous studies on the relationship between carbon uptake phenology and NEP primarily focus on growing season length (GSL). A longer GSL due to climate warming (Delpierre et al., 2015; Linderholm, 2006; Peñuelas and Filella, 2001) usually stimulates NEP (Baldocchi, 2008; Baldocchi and Wilson, 2001; Churkina et al., 2005; Dragoni et al., 2011; Richardson et al., 2013). Yet other studies have found no relationship between GSL and NEP (Dunn et al., 2007), or lower NEP with longer GSL (Hu et al., 2010b; Piao et al., 2007; Sacks et al., 2007). The reasons for this disparity are twofold; gross ecosystem productivity may be offset by concurrent increases in ecosystem respiration as NEP is the difference between the two, and longer GSLs may increase the likelihood of drought limitations to productivity.

With the advantage of quasi-continuous measurements of the net $\mathrm{CO}_{2}$ exchange by the eddy covariance method, strong relationships between net carbon uptake period (CUP) and annual NEP have been characterized (Baldocchi et al., 2001; Baldocchi et al., 2005; Richardson et al., 2010; Richardson et al., 2013; Wu and Chen, 2013; Wu et al., 2013). Overall, annual NEP is more strongly correlated with CUP than GSL (Piao et al., 2007; White and Nemani, 2003; Wu et al., 2013). While climate controls on GSL have been well studied (Chmielewski and Rötzer, 2001; Delpierre et al., 2015; Matsumoto et al., 2003; Richardson et al., 2013), our understanding of climate controls over CUP and thus NEP across different ecosystems is still limited.

In addition to the CUP, the maximum daily ecosystem NEP ( $\mathrm{NEP}_{\max }$, Fig. 1A) is another strong predictor of annual NEP, especially in temperate and boreal ecosystems that have obvious seasonal dynamics (Falge et al., 2002b; Xia et al., 2015; Zhou et al., 2016). With the same CUP, ecosystems that have a higher $\mathrm{NEP}_{\max }$ tend to have larger annual NEP (Fig. 1D) (Churkina et al., 2005). Although a longer CUP may increase annual NEP, associated warmer and drier summers may suppress summer $\mathrm{NEP}_{\max }$, potentially offsetting any annual NEP increase (e.g. Fig. 1E) (Angert et al., 2005; Ciais et al., 2005; Cleland et al., 2007). Moreover, a longer CUP may decrease annual NEP because an earlier onset of the growing season may result from a shallow snowpack or increased transpiration, leaving less available water in the soil in summer and limiting plant growth later in the growing season (Hu et al., 2010a; Kljun et al., 2006; Sacks et al., 2007).
Niemand et al. (2005) linked phenology observations to flux measurements in a Norway spruce forest and found that earlier spring phenology correlated well with increased NEP only when the drought year of 2003 was excluded, suggesting that water availability influences the relationship between CUP and annual NEP. These results indicate that the effects of summer water limitation on $\mathrm{NEP}_{\max }$ may potentially offset positive spring warming influences on spring NEP, leading to smaller changes in annual NEP than otherwise expected (Fig. 1E). In addition, autumn warming may also advance the ending of carbon uptake and decrease autumn NEP, resulting in a small change in annual NEP in response to climate warming (Fig. 1F). We tested the hypothesis that, by separating annual NEP variability into CUP and NEP ${ }_{\text {max }}$, we can better disentangle how meteorological drivers impact NEP variability in deciduous broadleaf forests (DBF), evergreen forests (EF), and grasslands (GRA) that experience pronounced seasonality in temperate and boreal climate zones.

In this study, we analyzed eddy covariance-measured $\mathrm{CO}_{2}$ flux and micrometeorological variables from 24 flux tower sites that have longterm (multi-year) quasi-continuous measurements. The specific questions addressed in this study include: (1) how are CUP and $\mathrm{NEP}_{\max }$ related to annual NEP in different biomes; (2) what are the climate factors that determine $\mathrm{NEP}_{\max }$ and the beginning (BDOY) and end (EDOY) of the CUP; and (3) how are seasonal NEP anomalies related to annual NEP anomalies?

\section{Data and methods}

\subsection{Site selection and data processing}

Surface-atmosphere $\mathrm{CO}_{2}$ flux and micrometeorological data used in this analysis were downloaded from standardized files of the FLUXNET LaThuille database released in 2007 (Baldocchi, 2008; Baldocchi et al., 2001). The data have been quality-controlled and gap-filled by consistent methods (Moffat et al., 2007; Papale et al., 2006; Reichstein et al., 2005). From the available 253 sites, we identified and examined temperate and boreal ecosystems $\left(38-62^{\circ} \mathrm{N},-125\right.$ to $24^{\circ} \mathrm{E}$; Table A1) that have clear seasonal dynamics. We only chose sites that have eight or more years of data for a total of 24 sites with 228 site-

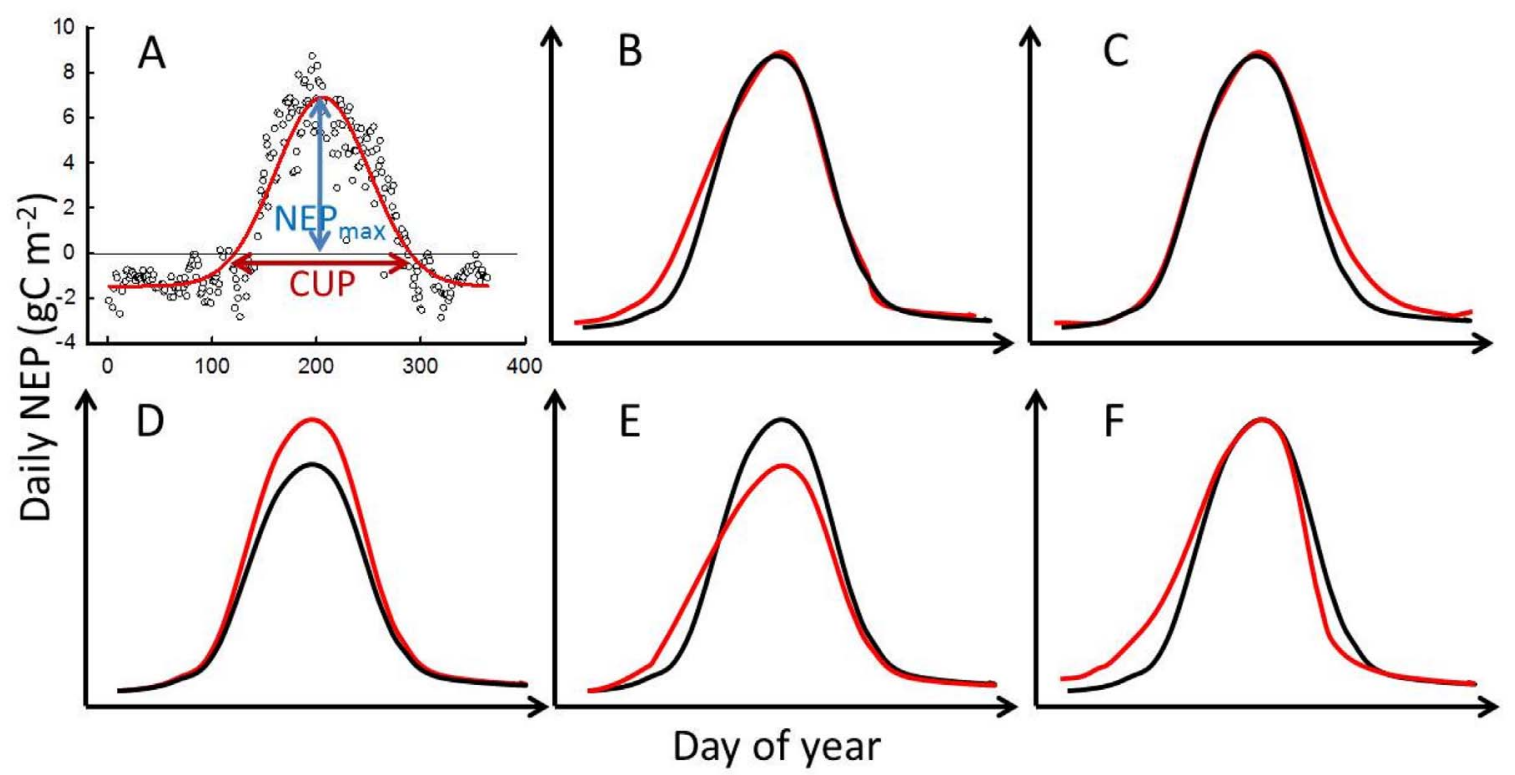

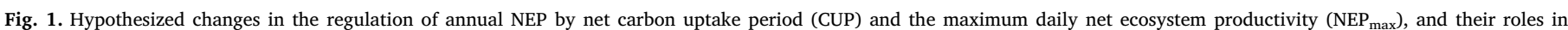

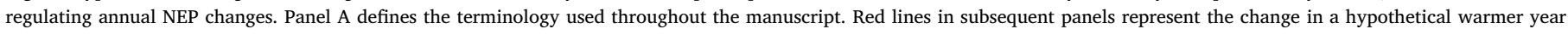

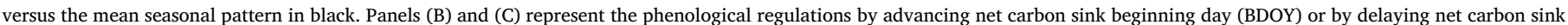

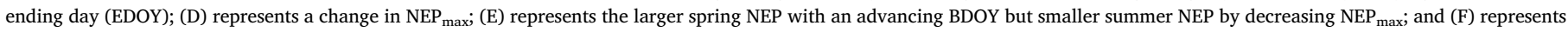

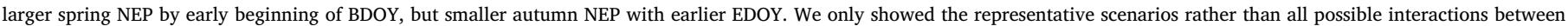
$\mathrm{NEP}_{\text {max }}, \mathrm{BDOY}$ and EDOY. 


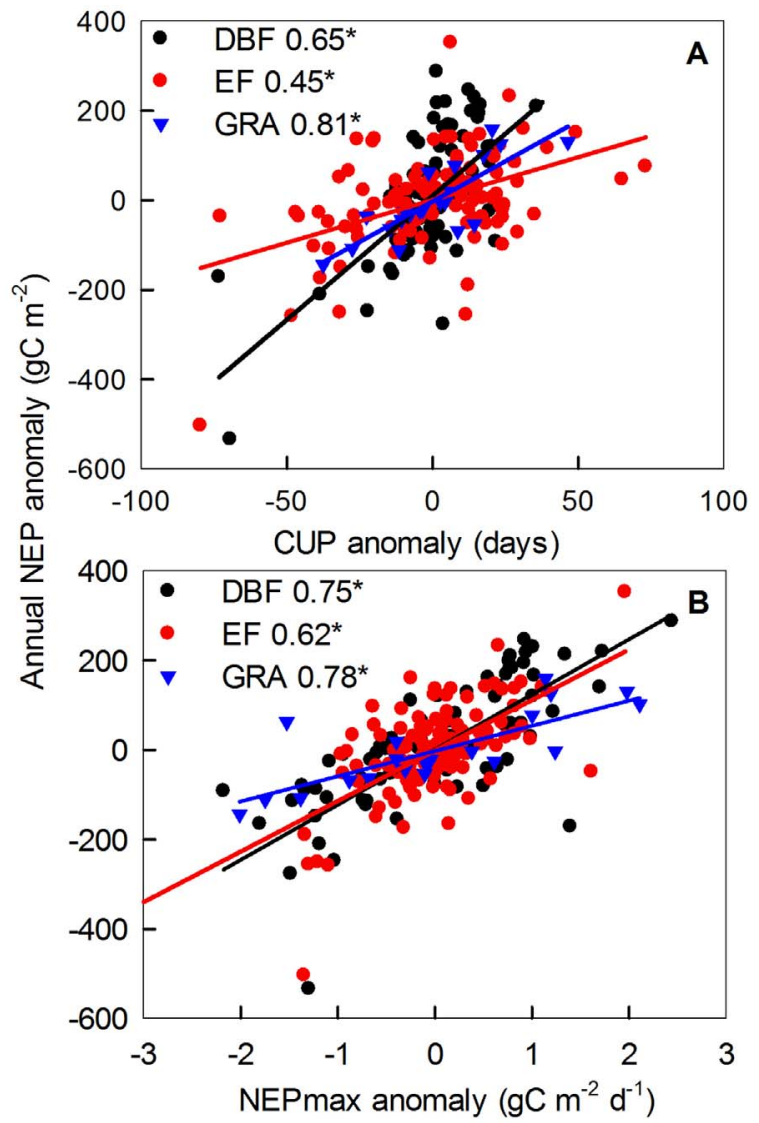

Fig. 2. (A) The changes in annual NEP anomalies with the anomalies of net carbon uptake period (CUP), and (B) the anomalies of maximum daily net ecosystem productivity $\left(\mathrm{NEP}_{\max }\right)$ in temperate and boreal deciduous broadleaf (DBF), evergreen forest (EF) and grassland (GRA) ecosystems. The numbers in the legends are $r$ values; all are significant at $P<0.001$.

years to investigate the interannual variability of climate and CUP and $\mathrm{NEP}_{\max }$, as well as seasonal and annual NEP (Table A1). Daily data for each site were used to calculate the seasonal and annual values of incoming solar global radiation $\left(\mathrm{R}_{\mathrm{g}}\right)$, air temperature $\left(\mathrm{T}_{\mathrm{a}}\right)$, precipitation (PPT), and daily $\mathrm{CO}_{2}$ fluxes (i.e., NEP, also called the net ecosystem exchange, NEE). These sites were divided into three groups based on International Geosphere-Biosphere Programme (IGBP) land cover classifications: deciduous broadleaf forests (DBF), evergreen forests (EF), and grasslands (GRA).

For each year, we calculated the seasonal and annual mean values of T, PPT, $R_{g}$, and NEP. The whole year was separated into the climatological seasons of winter (December-February), spring (March-May), summer (June-August), and autumn (September-November) in order to study seasonal changes in NEP in response to changes in CUP and $\mathrm{NEP}_{\text {max }}$. When the missing daily data exceeded $10 \%$ of the entire season (or year), the seasonal (or yearly) value was indicated as missing. On average, for the 24 sites, $8 \%$ of the years were rejected due to insufficient data. The years rejected varied from 7\% (US-Ha1) to 45\% (IT-Col) among sites.

\subsection{Definition and analysis}

We used a 10-day moving average to determine the beginning (BDOY) and ending (EDOY) day of positive ecosystem NEP for each year for each site (Fig. 1A, Table A2). Consistently, BDOY occurred in spring and EDOY appears in autumn at all the sites. We defined the net carbon uptake period (CUP) as the number of days between the BDOY and EDOY (Fig. 1A). Daily ecosystem carbon uptake exceeds carbon release during the CUP. CUP is related to, but need not be identical to,
GSL. For example, the beginning of CUP may start later than leaf onset when the leaves photosynthesize at a rate that outweighs ecosystem respiration. The CUP ends when ecosystem respiration is higher than photosynthesis although plant growth and $\mathrm{CO}_{2}$ uptake may continue. GSL in most cases will be longer than CUP because the balance between total ecosystem respiration and photosynthesis determines CUP (Churkina et al., 2005). The maximum daily NEP ( $\mathrm{NEP}_{\max }$ ) is defined as the maximum value of daily NEP, which was derived from the moving average curves of NEP seasonal dynamics (Fig. 1A). Interannual variation as a yearly anomaly was calculated for each site-year for each variable.

\subsection{Data analysis}

To examine the relationships between climate anomalies and the anomalies of BDOY, EDOY, and $\mathrm{NEP}_{\text {max }}$, as well as the anomalies in seasonal and annual NEP, we analyzed the data using simple linear regression. For testing the inequality of regression slopes among different vegetation types, the slopes between BDOY and EDOY anomalies, and seasonal or annual NEP anomalies for different seasons, we calculated $\mathrm{t}^{*}$ using $\left.\mathrm{t}^{*}=\left(b_{1}-b_{2}\right) / \sqrt{\left(s_{1}^{2}+s_{2}^{2}\right.}\right)$, where $b_{1}$ and $b_{2}$ are regression slopes, and $s_{1}$ and $s_{2}$ are the standard errors of regression slopes for the vegetation types or different seasons. The null hypothesis is that the slopes $b_{1}$ and $b_{2}$ are not significantly different at $\alpha=0.05$. We also used structural equation models to partition the total effect of variables on annual NEP into direct and indirect effects (Schumacker and Lomax, 2004; Vargas et al., 2010). A path model was developed to relate the anomalies of NEP to the anomalies of CUP and $\mathrm{NEP}_{\max }$, as well as the anomalies of seasonal climate factors in different ecosystems. The model was fitted using the 'lavaan' package (Rosseel, 2012) in R3.0.2 for Windows.

\section{Results}

\subsection{CUP and $N E P_{\max }$ in controlling $N E P$}

Across all the site-years, annual NEP anomalies were positively correlated with anomalies of CUP and $\mathrm{NEP}_{\max }$ across all three ecosystem types $(P<0.001$, Fig. $2 \mathrm{~A})$. The slope between CUP and NEP was significantly higher in DBF $\left(5.5 \mathrm{~g} \mathrm{C} \mathrm{m}^{-2}\right.$ per day) and GRA ( $3.6 \mathrm{~g} \mathrm{C} \mathrm{m}^{-2}$ per day) than in $\mathrm{EF}\left(1.9 \mathrm{~g} \mathrm{C} \mathrm{m}^{-2}\right.$ per day, Fig. $\left.2 \mathrm{~A}\right)$. Across all site-years, annual NEP increased by $107 \mathrm{~g} \mathrm{C} \mathrm{m}^{-2}$ per unit increase of $\mathrm{NEP}_{\max }\left(\mathrm{g} \mathrm{C} \mathrm{m}^{-2} \mathrm{~d}^{-1}\right)$ (Fig. 2B). The relationship between $\mathrm{NEP}_{\max }$ and NEP was similar between DBF $\left(123.2 \mathrm{~g} \mathrm{C} \mathrm{m}^{-2}\right)$ and EF $\left(112.9 \mathrm{~g} \mathrm{C} \mathrm{m}^{-2}\right)$ per unit increase of $\mathrm{NEP}_{\max }\left(\mathrm{g} \mathrm{C} \mathrm{m}^{-2} \mathrm{~d}^{-1}\right)$, and both were higher than that in GRA (56.3 $\mathrm{g} \mathrm{C} \mathrm{m}^{-2}$ ) (Fig. 2B). $\mathrm{NEP}_{\max }$ and CUP in combination explained $73,54,63 \%$ of the variation in annual NEP anomalies in DBF, $\mathrm{EF}$, and GRA, respectively, as quantified using the structural equation models (Fig. A1).

\subsection{Spring phenology and NEP}

BDOY was significantly correlated with spring temperature in DBF and $\mathrm{EF}$ (Fig. 3A), but not with spring precipitation or radiation in any biome $(P>0.05)$. BDOY advanced by 2.6 and 3.7 days per degree increase of spring temperature for DBF and EF, respectively (Fig. 3A). Early BDOY led to an increase in spring NEP in the three biomes, and annual NEP in DBF and EF (Fig. 3B and C). For example, spring NEP increased by $4.0,0.8$ and $1.6 \mathrm{~g} \mathrm{C} \mathrm{m}^{-2}$ per day advance of BDOY for DBF, EF, and GRA, respectively (Fig. 3B), while annual NEP increased by 6.6 and $2.1 \mathrm{~g} \mathrm{C} \mathrm{m}^{-2}$ per day advance of BDOY for DBF and $\mathrm{EF}$, respectively (Fig. 3C). All the spring climate factors in combination explained $37 \%$ and $16 \%$ of the variation in BDOY in DBF and $\mathrm{EF}$, respectively, but explained only $3 \%$ in GRA (Fig. A1). 

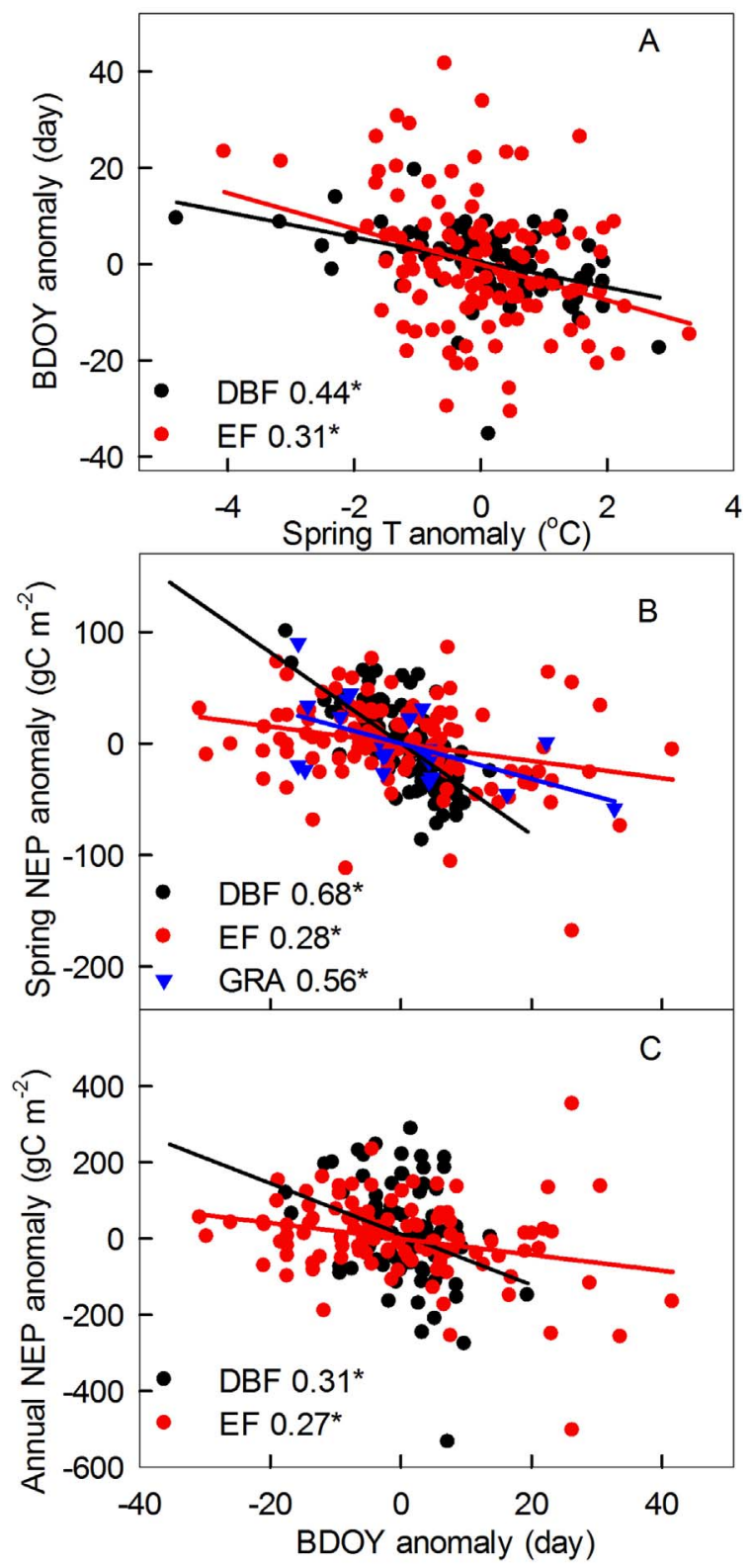

Fig. 3. (A) Spring phenology (net carbon sink beginning day, BDOY) in response to spring temperature change, and its contribution to spring (B) and annual (C) NEP anomalies in temperate and boreal deciduous broadleaf (DBF), evergreen forest (EF) and grassland (GRA) ecosystems. The numbers in the legends are $\mathrm{r}$ values; all are significant at $P<0.01$

\subsection{Autumn phenology and NEP}

EDOY anomalies were positively correlated with autumn temperature anomalies in DBF $(P<0.001$, Fig. 4A), with autumn radiation anomalies in EF $(P<0.01$, Fig. $4 \mathrm{~B})$, and with summer and autumn precipitation anomalies in GRA $(P<0.01$, Fig. 4 C). EDOY was later by 4.1 days per degree increase of autumn temperature in DBF (Fig. 4A), by 8 days per $100 \mathrm{MJ} \mathrm{m}^{-2}$ increase of radiation in $\mathrm{EF}$, and by 2.3 days per $10 \mathrm{~mm}$ increase of summer or autumn precipitation in GRA. Later EDOY led to an increase of autumn and annual NEP in the three biomes (Fig. 4D, E). Autumn NEP increased by $2.8,0.8$ and $0.5 \mathrm{~g} \mathrm{C} \mathrm{m}^{-2}$ per extra day of EDOY for DBF, EF and GRA, respectively (Fig. 4D), while annual NEP increased by $6.2,1.6$ and $2.6 \mathrm{~g} \mathrm{C} \mathrm{m}^{-2}$ per day, respectively (Fig. 4E). The autumn climate factors in combination explained $21 \%$ and $48 \%$ of the variation in EDOY in DBF and GRA, respectively, but explained only $10 \%$ in EF (Fig. A1).

\section{4. $N E P_{\max }$ and NEP}

$\mathrm{NEP}_{\text {max }}$ had no significant relationship with summer temperature or radiation in any biome $(P>0.05)$, but was negatively correlated with summer precipitation anomalies in DBF and positively correlated with summer precipitation anomalies in GRA (Fig. 5A). $\mathrm{NEP}_{\max }$ anomalies were related to summer NEP anomalies for all the three biomes with similar slopes (Fig. 5B). Summer climate factors in combination explained most (62\%) of the variation of $\mathrm{NEP}_{\max }$ in GRA but explained only $12 \%$ and $5 \%$ in DBF and EF (Fig. A1).

\subsection{Relationships among seasonal NEP}

Spring NEP anomalies were positively correlated with the summer, autumn, and winter NEP anomalies in DBF and EF, and the slope of this relationship did not differ between biomes (Fig. 6A-C). Summer NEP anomalies were correlated with autumn NEP anomalies in DBF and EF, and with winter NEP anomalies in EF (Fig. 6D, E). Autumn NEP anomalies were positively correlated with winter NEP anomalies only in EF (Fig. 6F). There were no significant relationships between seasonal NEP anomalies in GRA.

\section{Discussion}

We first discuss relationships between meteorological variables and the CUP, followed by a discussion of the relationships between CUP, $\mathrm{NEP}_{\text {max }}$, and NEP on the annual and seasonal bases.

4.1. The relationship between climate and the beginning of the net carbon uptake period

Our results show that interannual variability in ecosystem net carbon uptake phenology was sensitive to climate factors. Spring temperature drives the variability in BDOY, with an average advance of $2.6-4.5$ days ${ }^{\circ} \mathrm{C}^{-1}$ in warmer years (Fig. 3). The advancement of vegetation phenology in response to temperature is well documented in previous studies (Jeong et al., 2011; Julien and Sobrino, 2009; Keenan et al., 2014; Menzel and Fabian, 1999; Menzel et al., 2006; Piao et al., 2006; Schwartz et al., 2006). In an analysis of direct observations of plant phenology over Europe for 1971-2000, Menzel et al. (2006) detected an average advance of 0.25 days year ${ }^{-1}$ in spring onset. Using satellite-measured normalized difference vegetation index, Jeong et al. (2011) demonstrated that the start of the growing season advanced by 5.2 days during 1982-1999 over the Northern Hemisphere due to observed warming. Most of these previous studies used satellite-derived data to directly infer vegetation phenological parameters (Jeong et al., 2011; Julien and Sobrino, 2009).

Vegetation phenology may not necessarily reflect ecosystem net carbon uptake phenology (Bauerle et al., 2012; White and Nemani, 2003), but we found that BDOY responded to temperature anomalies in DBF and EF (Fig. 3). The phenology of DBF emerged to be more sensitive to the spring air temperature anomalies when compared with EF and GRA, likely because of the fundamental differences in phenological strategies among the biomes. For example, leaf flush in deciduous trees can occur rapidly compared to the reestablishment of photosynthetic mechanisms in conifers (Gu et al., 2008; Monson et al., 2005; Richardson et al., 2010), resulting in a smaller sensitivity of $\mathrm{BDOY}$ in response to a warmer spring in $\mathrm{EF}$ than in other biomes.

\subsection{The relationship between climate and the end of the net carbon uptake period}

Previous studies examining autumn phenology often focus on the impact of temperature on autumn phenology of vegetation. For example, Keenan et al. (2014) reported that warmer autumn temperatures lead to later senescence. The sensitivity of autumn phenology to a 

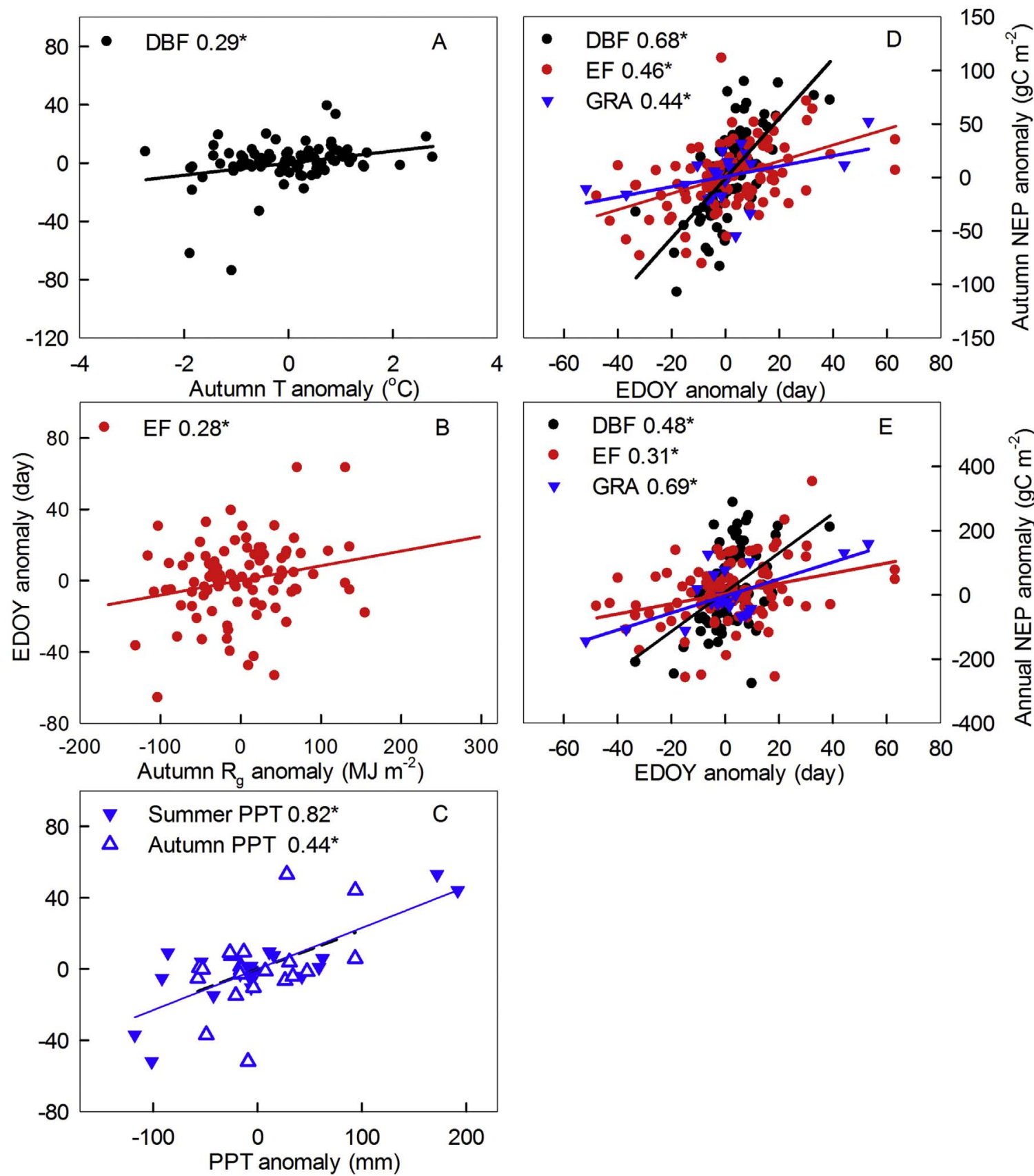

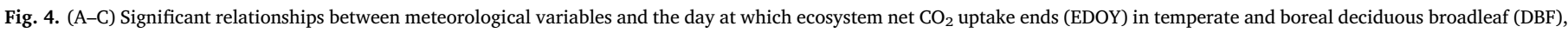

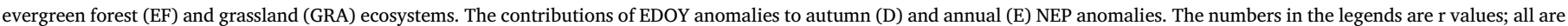
significant at $P<0.05$ ).

change from the mean temperature was similar across forest types, with a $1{ }^{\circ} \mathrm{C}$ difference from the mean temperature leading to a 1.8 day change in autumn senescence for DBF and a 6.3 day change in EF (Keenan et al., 2014). Using satellite NDVI data, Stockli and Vidale (2004) reported a delay of senescence in autumn by an average of 0.42 days year $^{-1}$ over Europe with observed climate warming, while Tucker et al. (2001) found an earlier onset of autumn in Eurasia in a warmer environment. The above-mentioned results suggest large uncertainties in estimating the key climate factors for vegetation phenology changes in autumn (Menzel et al., 2006).

Vegetation phenology does not necessarily reflect net carbon uptake phenology, and we found that the variability of EDOY was determined by different environmental factors in different biomes. EDOY occurred later with higher autumn temperature in $\mathrm{DBF}$, higher radiation in $\mathrm{EF}$, and more summer and autumn precipitation in GRA (Fig. 5). Our results indicate that precipitation and radiation, in addition to temperature, play important roles in regulating the EDOY in temperate and boreal ecosystems. More precipitation could improve soil water supply that enables longer carbon gain into autumn, while higher radiation may enable more net carbon gain as days are getting shorter and radiation is often limiting in autumn (Niu et al., 2011).

\subsection{The joint roles of CUP and $N E P_{\max }$ in regulating $N E P$}

The interannual variation in NEP was attributed to yearly anomalies in CUP and $\mathrm{NEP}_{\max }$ (Fig. 2), which in combination explained $54-73 \%$ of changes in annual NEP in the three biomes (Fig. A1). In line with our findings, Xia et al. (2015) and Zhou et al. (2016) recently proposed that 

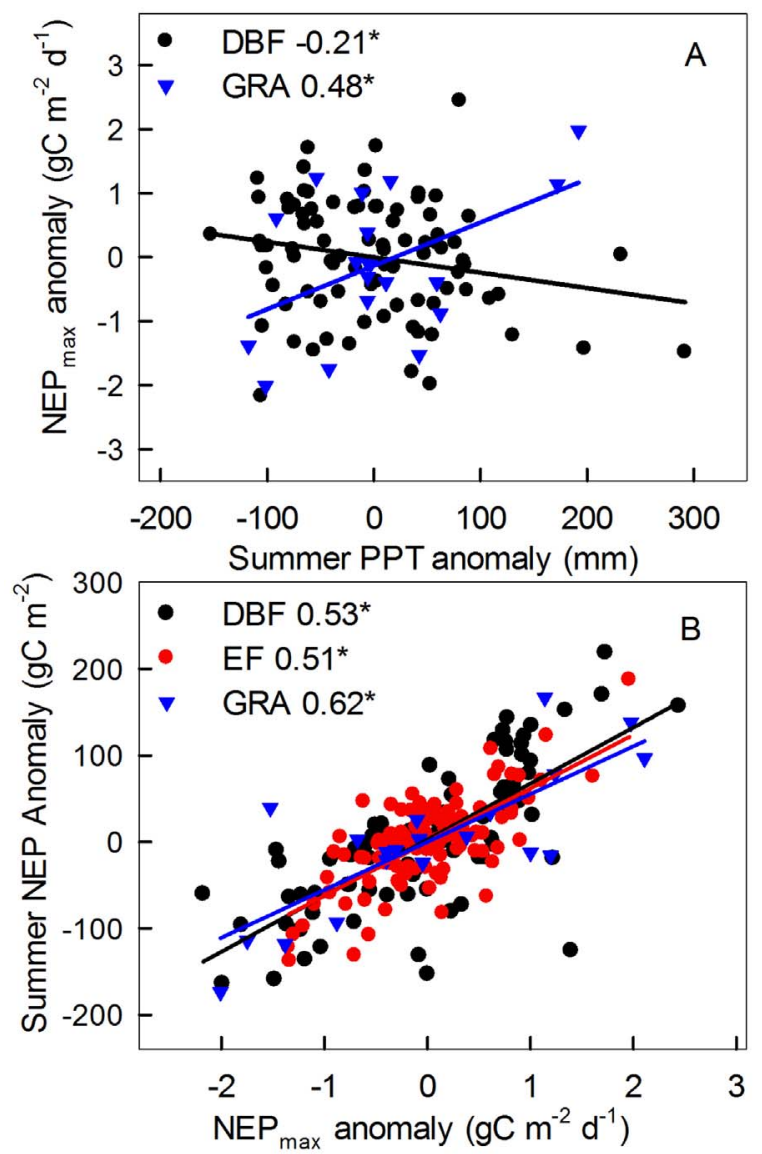

Fig. 5. (A) The relationship between summer precipitation (PPT) and maximum daily net ecosystem productivity $\left(\mathrm{NEP}_{\max }\right)$ in temperate and boreal deciduous broadleaf (DBF) and grassland (GRA) ecosystems. (B) The contribution of $\mathrm{NEP}_{\text {max }}$ anomalies to summer NEP anomalies at all three study biomes. The numbers in the legends are $\mathrm{r}$ values; all are significant at $P<0.05$.

more than $90 \%$ of annual gross primary productivity (GPP) can be explained by the combination of growing season length and the maximum daily GPP in temperate, boreal, and arctic ecosystems. These findings highlighted the important role of $\mathrm{GPP}_{\max }$ and phenology in controlling production and emphasize the importance of extending such an analysis to account for NEP in addition to GPP.

We found that an early onset of net carbon uptake enhanced spring and annual NEP (Fig. 3), while a delay of EDOY increased autumn and annual NEP (Fig. 4), indicating the importance of CUP in regulating carbon sequestration in temperate and boreal ecosystems. The observed link between CUP and annual NEP in temperate and boreal ecosystems are consistent with the results of Baldocchi et al. (2001), Baldocchi (2008), and Wu and Chen (2013). Compared to previous studies, this study emphasized different sensitivities between climate and NEP among biomes and between seasons. Spring, autumn, and annual NEP changed more in DBF than in EF and GRA with the same change in BDOY or EDOY. This suggests a higher sensitivity of NEP to phenology changes in DBF than other biomes. Some previous studies also reported that ecosystem productivity in DBF was more sensitive than EF to carbon uptake period (Churkina et al., 2005; Wu et al., 2013). Using flux data, Wu et al. (2013) quantified that a one-day increase in CUP led to a 3.3 and $1.5 \mathrm{~g} \mathrm{C} \mathrm{m}^{2} \mathrm{y}^{-1}$ increase in annual NEP in DBF and EF, respectively. These results indicate that $\mathrm{DBF}$ tends to have a higher productivity during the growing season than $\mathrm{EF}$ due to the fundamental differences in physiological strategies between the two biomes (Barr et al., 2009; Falge et al., 2002a; Givnish, 2002; Richardson et al., 2009). Deciduous broadleaf tree species evolved millions of years after conifers and are much more efficient in assimilation per unit leaf surface-the luxury of shedding leaves in winter. DBF are well known for having a higher maximum photosynthetic capacity, which is be offset by a shorter vegetation period (Roser et al., 2002; Schulze et al., 1977). The observed differences between EF and DBF in phenology-productivity relationships have ecological implications, especially in the light of climate change effects on phenology, as phenology models should predict ecosystem response to climate change in different ways for different biomes.

In addition to CUP, $\mathrm{NEP}_{\max }$ also contributed to the interannual variability of ecosystem NEP, especially during summer (Fig. 5). Our results showed that summer precipitation was related to $\mathrm{NEP}_{\max }$ in GRA and DBF, indicating that increases in annual NEP due to increases in CUP may be offset by the influence of summer precipitation on $\mathrm{NEP}_{\text {max }}$. These results suggest that CUP and $\mathrm{NEP}_{\max }$ may play different roles in regulating the variability of annual NEP, depending on their interactions.

\subsection{Seasonal NEP contributions to annual NEP anomalies}

NEP anomalies in different seasons were related to annual NEP anomalies as expected (Fig. 6). Spring phenology was more strongly related to spring NEP than to annual NEP, suggesting that annual fluxes are much more variable because they are affected by weather events in other seasons. For example, in grasslands, although early onset of BDOY led to an increase of spring NEP, annual NEP showed no relationship with BDOY anomalies (Fig. 3). This is possibly due to the limitations of summer precipitation, which led to lower summer NEP (Fig. 1E). The insignificant relationship between spring NEP anomalies and NEP anomalies in other seasons in GRA (Fig. 6) also indicates that the depression of NEP in other seasons may exceed the legacy effects of spring NEP on later seasons. DBF and EF showed strong lag effects of spring NEP on the summer/autumn NEP (Fig. 6), suggesting that spring phenology plays an important role in determining the seasonal and annual NEP in these two biomes. Flux anomalies in other seasons may also partly contribute additional variability to the annual NEP.

The various relationships between NEP anomalies in different seasons indicate that the interannual variability of NEP can only be better understood by fully addressing the different responses of seasonal NEP to climate and meteorological variability. If we connect annual NEP anomalies to climate factors only at annual time scales, we might miss many significant relationships between seasonal NEP and climate factors at the ecosystem scale. Temperature is the main factor controlling the interannual variability of terrestrial NEP at the global scale (Jung et al., 2017; Wang et al., 2013; Wang et al., 2014), as the ecosystem and regional effects of precipitation compensate for each other (Ahlström et al., 2015; Poulter et al., 2014; Zeng et al., 2005). Understanding the links between ecosystem and global scale responses to climate variability is an important avenue of future research, and we must extend our understanding of the controls over NEP to tropical and subtropical ecosystems to do so from the "bottom up" using ecosystemscale observations.

\section{Conclusions}

By analyzing eddy covariance $\mathrm{CO}_{2}$ fluxes from 24 flux tower sites, this study examined the responses of CUP and $\mathrm{NEP}_{\max }$ to climate factors in temperate and boreal ecosystems with pronounced seasonality. Spring temperature was the primary controlling factor for BDOY, but the controlling factors for EDOY were different among biomes. Summer precipitation was the main factor effecting $\mathrm{NEP}_{\max }$ for DBF and GRA. Because these critical phenology and physiology-relevant variables were controlled by different seasonal environmental factors, there existed complex relationships among NEP anomalies in different seasons. This study provides a fundamental understanding of the role of ecosystem level phenology and physiology in regulating ecosystem carbon sequestration across temperate and boreal ecosystems, and 


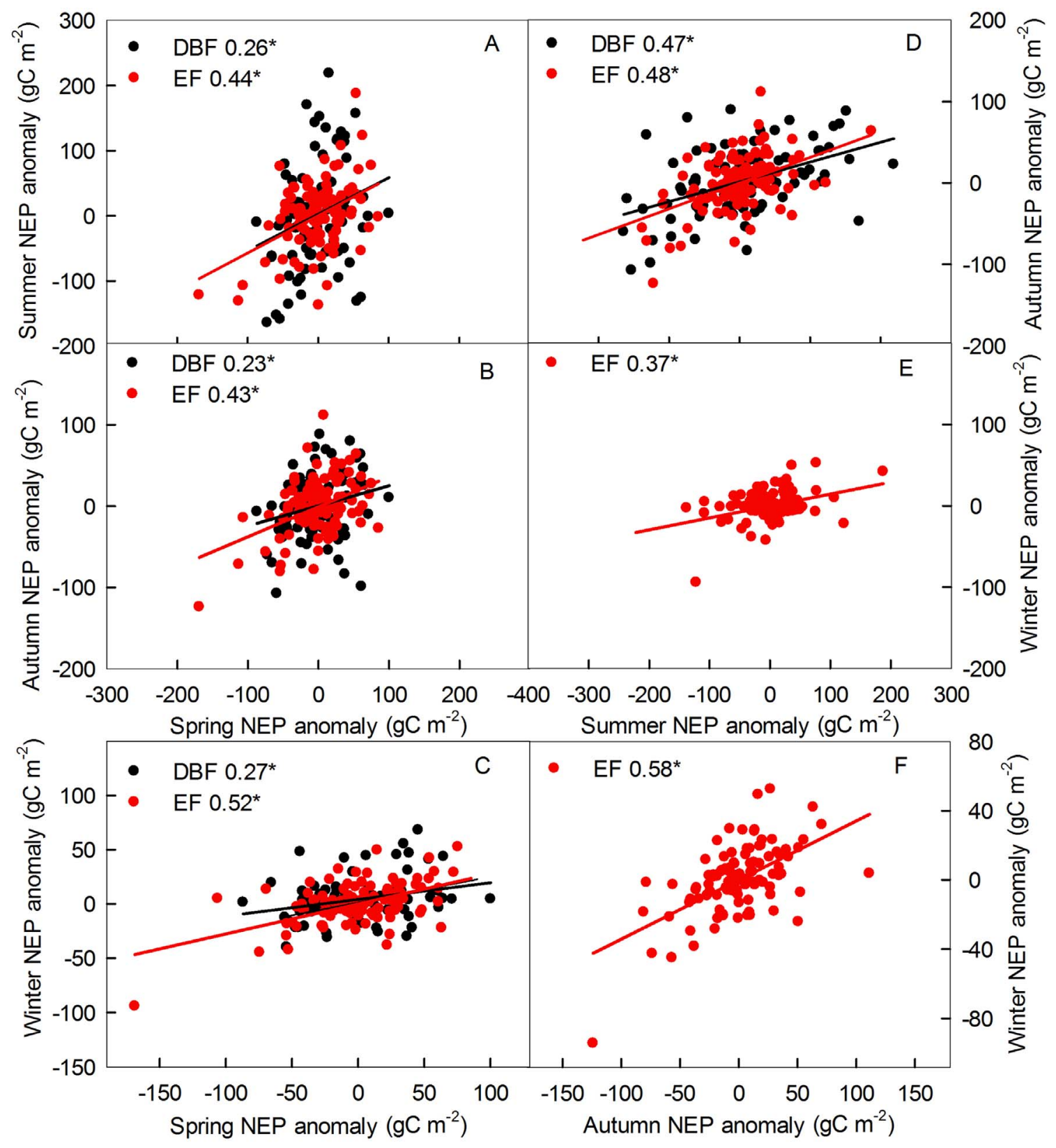

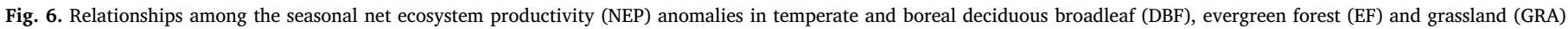

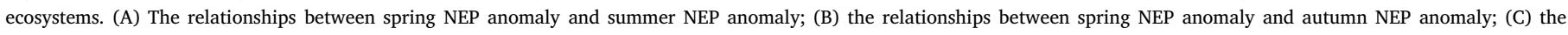

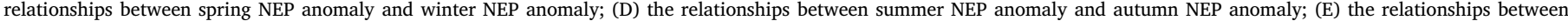

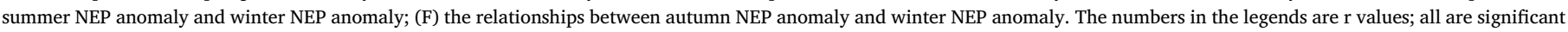
at $P<0.05$.

future studies should extend our understanding to regions with lesspronounced seasonality to improve our understanding of the relationship between climate and ecosystem carbon exchange.

\section{Acknowledgements}

We thank the FLUXNET site PIs for contributing data, the agencies and institutions that funded long-term measurements at these sites, and the networks to which the sites belong, particularly AmeriFlux and CarboEuropeIP. This work used eddy covariance data acquired by the FLUXNET community and in particular by the following networks: AmeriFlux (U.S. Department of Energy, Biological and Environmental Research, Terrestrial Carbon Program (DE-FG02-04ER63917 and DEFG02-04ER63911)), AfriFl, AsiaFlux, CarboAfrica, CarboEuropeIP, CarboItaly, CarboMont, ChinaFlux, Fluxnet-Canada (supported by
CFCAS, NSERC, BIOCAP, Environment Canada, and NRCan), GreenGrass, KoFlux, LBA, NECC, OzFlux, TCOS-Siberia, USCCC. We acknowledge the financial support to the eddy covariance data harmonization provided by CarboEuropeIP, FAO-GTOS-TCO, iLEAPS, Max Planck Institute for Biogeochemistry, National Science Foundation, University of Tuscia, Université Laval and Environment Canada and US Department of Energy and the database development and technical support from Berkeley Water Center, Lawrence Berkeley National Laboratory, Microsoft Research eScience, Oak Ridge National Laboratory, University of California-Berkeley, University of Virginia. This work was financially supported by the National Natural Science Foundation of China (31625006), the Ministry of Science and Technology of China (2013CB956300), CAS Strategic Priority Research Program (XDA05050702), and the "Thousand Youth Talents Plan". US-UMB site were supported by the Midwestern Regional Center 
of NICCR (DE-FC02-06ER64158), as part of the FASET project and NSF grant DEB-0911461. PCS acknowledges contributions from the U.S. National Science Foundation $(1552976,1632810)$ and the USDA
National Institutes of Food and Agriculture Hatch project 228396. ZF gratefully acknowledges the China Scholarship Council for the financial support of a 24-month study at Montana State University.

\section{Appendix A}

See Tables A1 and A2 and Fig. A1.

Table A1

Site characteristics, climatic index, and studied period of eddy covariance research sites in this analysis.

\begin{tabular}{|c|c|c|c|c|c|c|c|}
\hline Site name & Veg $^{1}$ & Lat $^{*}$ & Lon $^{* *}$ & $\mathrm{PPT}^{2}(\mathrm{~mm})$ & $\mathrm{Ta}\left({ }^{\circ} \mathrm{C}\right)$ & Period & References \\
\hline AT-Neu & GRA & 47.12 & 11.32 & 1040.4 & 6.3 & 2002-2009 & (Wohlfahrt et al., 2008) \\
\hline BE-Bra & $\mathrm{EF}$ & 51.31 & 4.52 & 742.7 & 10.0 & 2000-2009 & (Gielen et al., 2010) \\
\hline BE-Vie & $\mathrm{EF}$ & 50.31 & 6.00 & 1065.1 & 7.4 & 1996-2007 & (Aubinet et al., 2001) \\
\hline CA-Ca1 & $\mathrm{EF}$ & 49.87 & -125.33 & 1369.2 & 9.9 & 1998-2005 & (Humphreys et al., 2006) \\
\hline CA-Let & GRA & 49.71 & -112.94 & 349.9 & 6.2 & 1998-2005 & (Flanagan et al., 2002) \\
\hline CA-Man & $\mathrm{EF}$ & 55.88 & -98.48 & 515 & -1.2 & 1995-2003 & (Dunn et al., 2007) \\
\hline CA-Oas & DBF & 53.63 & -106.2 & 428.5 & 0.3 & 1997-2005 & (Black et al., 2000) \\
\hline DE-Hai & DBF & 51.08 & 10.45 & 780.3 & 7.2 & $2000-2007$ & (Knohl et al., 2003) \\
\hline DE-Tha & $\mathrm{EF}$ & 50.96 & 13.57 & 643.1 & 8.1 & 1997-2008 & (Grunwald and Bernhofer, 2007) \\
\hline DK-Sor & DBF & 55.49 & 11.65 & 952 & 8.7 & 1998-2009 & (Pilegaard et al., 2003) \\
\hline FI-Hyy & $\mathrm{EF}$ & 61.85 & 24.29 & 620.2 & 2.2 & 1997-2008 & (Suni et al., 2003) \\
\hline FR-Pue & $\mathrm{EF}$ & 43.74 & 3.59 & 734.5 & 12.9 & $2001-2008$ & (Rambal et al., 2004) \\
\hline FR-Hes & DBF & 48.67 & 7.06 & 793.3 & 9.2 & 1997-2008 & (Granier et al., 2000) \\
\hline IT-Ren & $\mathrm{EF}$ & 46.59 & 11.43 & 964.7 & 6.2 & 2001-2009 & (Montagnani et al., 2009) \\
\hline IT-Col & DBF & 41.85 & 13.59 & 970.9 & 7.3 & 1997-2007 & (Van Dijk and Dolman, 2004) \\
\hline US-Blo & $\mathrm{EF}$ & 38.9 & -120.63 & 1630 & 12.5 & 1999-2006 & (Goldstein et al., 2000) \\
\hline US-MMS & DBF & 39.32 & -86.41 & 1031.6 & 10.8 & 1999-2006 & (Schmid et al., 2000) \\
\hline IT-Ro1 & DBF & 42.41 & 11.93 & 763.7 & 15.3 & $2001-2008$ & (Rey et al., 2002) \\
\hline NL-Loo & $\mathrm{EF}$ & 52.17 & 5.74 & 786.2 & 9.4 & 1997-2009 & (Dolman et al., 2002) \\
\hline US-Ha1 & $\mathrm{DBF}$ & 43.54 & -72.17 & 1071 & 6.6 & 1993-2006 & (Urbanski et al., 2007) \\
\hline US-Ho1 & $\mathrm{EF}$ & 45.2 & -68.74 & 1070.3 & 5.3 & 1996-2004 & (Hollinger et al., 2004) \\
\hline US-UMB & DBF & 45.56 & -84.71 & 803.4 & 5.8 & 1999-2006 & (Gough et al., 2008) \\
\hline US-NR1 & $\mathrm{EF}$ & 40.03 & -105.54 & 595.2 & 0.4 & 1999-2007 & (Monson et al., 2002) \\
\hline US-Var & GRA & 38.41 & -120.95 & 543.9 & 15.9 & 2001-2008 & (Xu and Baldocchi, 2004) \\
\hline
\end{tabular}

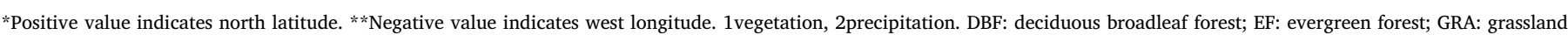

Table A2

The mean and variability of the beginning date (BDOY) and ending date (EDOY) of net carbon uptake for each study site during the study period.

\begin{tabular}{|c|c|c|c|c|c|}
\hline \multirow[t]{2}{*}{ Sites } & \multirow[t]{2}{*}{ Vegetation } & \multicolumn{2}{|l|}{ BDOY } & \multicolumn{2}{|l|}{ EDOY } \\
\hline & & Mean & SD & Mean & SD \\
\hline CA-Oas & DBF & 135.6 & 10.8 & 251.4 & 4.2 \\
\hline DE-Hai & DBF & 116.0 & 4.5 & 280.3 & 5.6 \\
\hline DK-Sor & DBF & 108.7 & 6.4 & 262.8 & 8.3 \\
\hline FR-Hes & $\mathrm{DBF}$ & 18.4 & 23.0 & 337.3 & 19.5 \\
\hline IT-Col & DBF & 53.3 & 12.7 & 322.3 & 11.5 \\
\hline US-MMS & DBF & 31.3 & 9.9 & 277.8 & 21.3 \\
\hline IT-Ro1 & DBF & 30.7 & 21.6 & 306.4 & 31.7 \\
\hline US-Ha1 & DBF & 77.2 & 5.1 & 294.0 & 18.9 \\
\hline US-UMB & DBF & 110.0 & 8.1 & 285.9 & 5.1 \\
\hline BE-Bra & $\mathrm{EF}$ & 91.3 & 16.2 & 267.7 & 7.7 \\
\hline BE-Vie & $\mathrm{EF}$ & 45.9 & 16.3 & 292.6 & 10.9 \\
\hline CA-Ca1 & $\mathrm{EF}$ & 12.9 & 6.4 & 290.8 & 54.1 \\
\hline CA-Man & $\mathrm{EF}$ & 98.8 & 17.8 & 247.6 & 16.7 \\
\hline DE-Tha & $\mathrm{EF}$ & 42.0 & 17.1 & 314.7 & 13.4 \\
\hline FI-Hyy & $\mathrm{EF}$ & 85.8 & 10.1 & 260.8 & 11.4 \\
\hline FR-Pue & $\mathrm{EF}$ & 108.1 & 4.3 & 277.9 & 16.0 \\
\hline IT-Ren & $\mathrm{EF}$ & 111.4 & 12.7 & 278.9 & 12.8 \\
\hline US-Blo & $\mathrm{EF}$ & 91.3 & 11.6 & 269.0 & 35.7 \\
\hline NL-Loo & $\mathrm{EF}$ & 133.2 & 5.3 & 274.5 & 4.1 \\
\hline US-Ho1 & $\mathrm{EF}$ & 109.6 & 3.7 & 279.0 & 5.9 \\
\hline US-NR1 & $\mathrm{EF}$ & 132.3 & 7.5 & 267.4 & 5.3 \\
\hline AT-Neu & GRA & 89.7 & 4.5 & 255.1 & 4.0 \\
\hline CA-Let & GRA & 110.7 & 13.8 & 219.2 & 35.3 \\
\hline US-Var & GRA & 16.7 & 15.8 & 134.4 & 7.1 \\
\hline
\end{tabular}




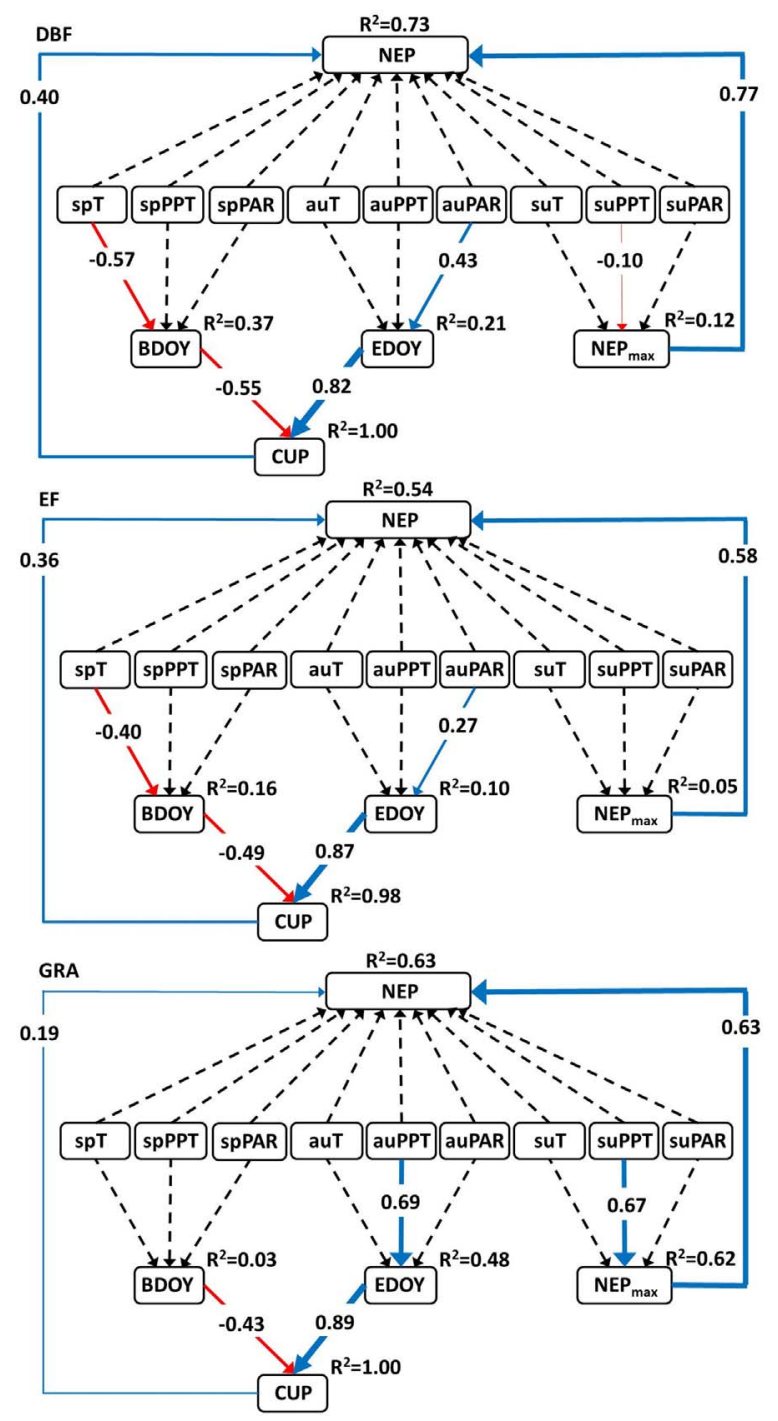

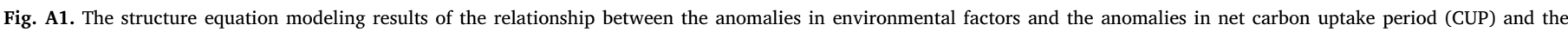

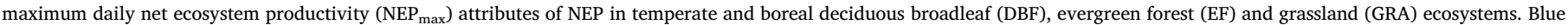

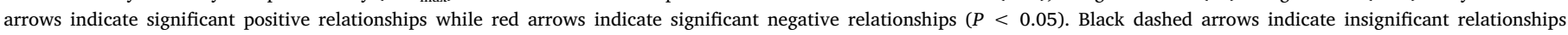

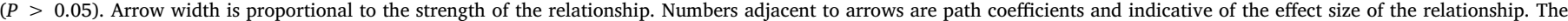

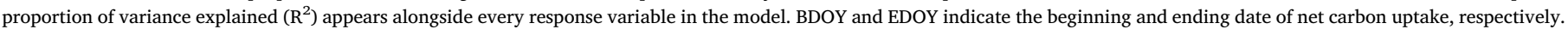
T, PPT, and PAR indicate temperature, precipitation, and radiation, respectively. Sp, su, and au indicate spring, summer, and autumn, respectively.

\section{References}

Ahlström, A., et al., 2015. The dominant role of semi-arid ecosystems in the trend and variability of the land CO2 sink. Science 348 (6237), 895-899.

Angert, A., et al., 2005. Drier summers cancel out the CO2 uptake enhancement induced by warmer springs. Proc. Natl. Acad. Sci. U. S. A. 102 (31), 10823-10827.

Aubinet, M., et al., 2001. Long term carbon dioxide exchange above a mixed forest in the Belgian Ardennes. Agric. Forest Meteorol. 108 (4), 293-315.

Baldocchi, D.D., Wilson, K.B., 2001. Modeling CO2 and water vapor exchange of a temperate broadleaved forest across hourly to decadal time scales. Ecol. Modell. 142 (1), 155-184.

Baldocchi, D., et al., 2001. FLUXNET: a new tool to study the temporal and spatial variability of ecosystem-scale carbon dioxide, water vapor, and energy flux densities. Bull. Am. Meteorol. Soc. 82 (11), 2415-2434.

Baldocchi, D.D., et al., 2005. Predicting the onset of net carbon uptake by deciduous forests with soil temperature and climate data: a synthesis of FLUXNET data. Int. J. Biometeorol. 49 (6), 377-387.

Baldocchi, D., 2008. TURNER REVIEW No. 15. 'Breathing'of the terrestrial biosphere: lessons learned from a global network of carbon dioxide flux measurement systems. Aust. J. Bot. 56 (1), 1-26.

Barr, A., Black, T.A., McCaughey, H., 2009. Climatic and Phenological Controls of the Carbon and Energy Balances of Three Contrasting Boreal Forest Ecosystems in Western Canada, Phenology of Ecosystem Processes. Springerpp. 3-34.

Bauerle, W.L., et al., 2012. Photoperiodic regulation of the seasonal pattern of photosynthetic capacity and the implications for carbon cycling. Proc. Natl. Acad. Sci. 109 (22), 8612-8617.
Black, T.A., et al., 2000. Increased carbon sequestration by a boreal deciduous forest in years with a warm spring. Geophys. Res. Lett. 27 (9), 1271-1274.

Chmielewski, F.-M., Rötzer, T., 2001. Response of tree phenology to climate change across Europe. Agric. Forest Meteorol. 108 (2), 101-112.

Churkina, G., Schimel, D., Braswell, B.H., Xiao, X., 2005. Spatial analysis of growing season length control over net ecosystem exchange. Global Change Biol. 11 (10), 1777-1787.

Ciais, P., et al., 2005. Europe-wide reduction in primary productivity caused by the heat and drought in 2003. Nature 437 (7058), 529-533.

Cleland, E.E., Chuine, I., Menzel, A., Mooney, H.A., Schwartz, M.D., 2007. Shifting plant phenology in response to global change. Trends Ecol. Evol. 22 (7), 357-365.

Delpierre, N., et al., 2015. Temperate and boreal forest tree phenology: from organ-scale processes to terrestrial ecosystem models. Ann. Forest Sci. 1-21.

Dolman, A.J., Moors, E.J., Elbers, J.A., 2002. The carbon uptake of a mid latitude pine forest growing on sandy soil. Agric. Forest Meteorol. 111 (3), 157-170.

Dragoni, D., et al., 2011. Evidence of increased net ecosystem productivity associated with a longer vegetated season in a deciduous forest in south-central Indiana, USA. Global Change Biol. 17 (2), 886-897.

Dunn, A.L., Barford, C.C., Wofsy, S.C., Goulden, M.L., Daube, B.C., 2007. A long-term record of carbon exchange in a boreal black spruce forest: means, responses to interannual variability, and decadal trends. Global Change Biol. 13 (3), 577-590.

Falge, E., et al., 2002a. Seasonality of ecosystem respiration and gross primary production as derived from FLUXNET measurements. Agric. Forest Meteorol. 113 (1), 53-74.

Falge, E., et al., 2002b. Phase and amplitude of ecosystem carbon release and uptake potentials as derived from FLUXNET measurements. Agric. Forest Meteorol. 113 (1), 75-95. 
Flanagan, L.B., Wever, L.A., Carlson, P.J., 2002. Seasonal and interannual variation in carbon dioxide exchange and carbon balance in a northern temperate grassland. Global Change Biol. 8 (7), 599-615.

Gielen, B., et al., 2010. Decadal water balance of a temperate Scots pine forest (Pinus sylvestris L.) based on measurements and modelling. Biogeosciences 7 (4), 1247-1261.

Givnish, T.J., 2002. Adaptive significance of evergreen vs. deciduous leaves: solving the triple paradox. Silva Fennica 36 (3), 703-743.

Goldstein, A.H., et al., 2000. Effects of climate variability on the carbon dioxide, water, and sensible heat fluxes above a ponderosa pine plantation in the Sierra Nevada (CA). Agric. Forest Meteorol. 101 (2-3), 113-129.

Gough, C.M., Vogel, C.S., Schmid, H.P., Su, H.B., Curtis, P.S., 2008. Multi-year convergence of biometric and meteorological estimates of forest carbon storage. Agric. Forest Meteorol. 148 (2), 158-170.

Granier, A., et al., 2000. The carbon balance of a young Beech forest. Funct. Ecol. 14 (3), 312-325.

Grunwald, T., Bernhofer, C., 2007. A decade of carbon, water and energy flux measurements of an old spruce forest at the Anchor Station Tharandt. Tellus B 59 (3), 387-396.

Gu, L., et al., 2008. The 2007 Eastern US spring freeze: increased cold damage in a warming world? Bioscience 58 (3), 253-262.

Gu, L., et al., 2009. Characterizing the Seasonal Dynamics of Plant Community Photosynthesis Across a Range of Vegetation Types, Phenology of Ecosystem Processes. Springerpp. 35-58.

Hollinger, D.Y., et al., 2004. Spatial and temporal variability in forest-atmosphere CO2 exchange. Global Change Biol. 10 (10), 1689-1706.

Hu, F.S., et al., 2010a. Tundra burning in Alaska: linkages to climatic change and sea ice retreat. J. Geophys. Res. Biogeo 115.

Hu, J., Moore, D.J., Burns, S.P., Monson, R.K., 2010b. Longer growing seasons lead to less carbon sequestration by a subalpine forest. Global Change Biol. 16 (2), 771-783.

Humphreys, E.R., et al., 2006. Carbon dioxide fluxes in coastal Douglas-fir stands at different stages of development after clearcut harvesting. Agric. Forest Meteorol. 140 (1-4), 6-22.

IPCC, 2013. Climate Change 2013: The Physical Science Basis. IPCC.

Jeong, S.-J., Ho, C.-H., Gim, H.-J., Brown, M.E., 2011. Phenology shifts at start vs. end of growing season in temperate vegetation over the Northern Hemisphere for the period 1982-2008. Global Change Biol. 17 (7), 2385-2399.

Julien, Y., Sobrino, J., 2009. Global land surface phenology trends from GIMMS database. Int. J. Remote Sens. 30 (13), 3495-3513.

Jung, M., et al., 2017. Compensatory water effects link yearly global land CO2 sink changes to temperature. Nature 541 (7638), 516-520.

Keenan, T.F., et al., 2014. Net carbon uptake has increased through warming-induced changes in temperate forest phenology. Nat. Clim. Change 4 (7), 598-604.

Kljun, N., et al., 2006. Response of net ecosystem productivity of three boreal forest stands to drought. Ecosystems 9 (7), 1128-1144.

Knohl, A., Schulze, E.D., Kolle, O., Buchmann, N., 2003. Large carbon uptake by an unmanaged 250-year-old deciduous forest in Central Germany. Agric. Forest Meteorol. 118 (3-4), 151-167.

Linderholm, H.W., 2006. Growing season changes in the last century. Agric. Forest Meteorol. 137 (1), 1-14.

Matsumoto, K., Ohta, T., Irasawa, M., Nakamura, T., 2003. Climate change and extension of the Ginkgo biloba L. growing season in Japan. Global Change Biol. 9 (11), $1634-1642$.

Menzel, A., Fabian, P., 1999. Growing season extended in Europe. Nature 397 (6721), 659.

Menzel, A., et al., 2006. European phenological response to climate change matches the warming pattern. Global Change Biol. 12 (10), 1969-1976.

Moffat, A.M., et al., 2007. Comprehensive comparison of gap-filling techniques for eddy covariance net carbon fluxes. Agric. Forest Meteorol. 147 (3-4), 209-232.

Monson, R.K., et al., 2002. Carbon sequestration in a high-elevation, subalpine forest. Global Change Biol. 8 (5), 459-478.

Monson, R.K., et al., 2005. Climatic influences on net ecosystem CO2 exchange during the transition from wintertime carbon source to springtime carbon sink in a highelevation, subalpine forest. Oecologia 146 (1), 130-147.

Montagnani, L., et al., 2009. A new mass conservation approach to the study of $\mathrm{CO} 2$ advection in an alpine forest. J. Geophys. Res-Atmos. 114. http://dx.doi.org/10. 1029/2008jd010650.

Niemand, C., Kostner, B., Prasse, H., Grunwald, T., Bernhofer, C., 2005. Relating tree phenology with annual carbon fluxes at Tharandt forest. Meteorol. Z. 14 (2), 197-202.

Niu, S., et al., 2011. Seasonal hysteresis of net ecosystem exchange in response to temperature change: patterns and causes. Global Change Biol. 17 (10), 3102-3114.

Papale, D., et al., 2006. Towards a standardized processing of Net Ecosystem Exchange measured with eddy covariance technique: algorithms and uncertainty estimation. Biogeosciences 3 (4), 571-583.

Peñuelas, J., Filella, I., 2001. Respoonses to a warming world. Science 294 (5543), 793.

Piao, S., Fang, J., Zhou, L., Ciais, P., Zhu, B., 2006. Variations in satellite-derived phenology in China's temperate vegetation. Global Change Biol. 12 (4), 672-685.
Piao, S., Friedlingstein, P., Ciais, P., Viovy, N., Demarty, J., 2007. Growing season extension and its impact on terrestrial carbon cycle in the Northern Hemisphere over the past 2 decades. Global Biogeochem. Cycles 21 (3).

Pilegaard, K., et al., 2003. Field measurements of atmosphere-biosphere interactions in a Danish beech forest. Boreal Environ. Res. 8 (4), 315-333.

Poulter, B., et al., 2014. Contribution of semi-arid ecosystems to interannual variability of the global carbon cycle. Nature 509 (7502), 600-603.

Rambal, S., Joffre, R., Ourcival, J.M., Cavender-Bares, J., Rocheteau, A., 2004. The growth respiration component in eddy $\mathrm{CO} 2$ flux from a Quercus ilex mediterranean forest. Global Change Biol. 10 (9), 1460-1469.

Reichstein, M., et al., 2005. On the separation of net ecosystem exchange into assimilation and ecosystem respiration: review and improved algorithm. Global Change Biol. 11 (9), 1424-1439.

Rey, A., et al., 2002. Annual variation in soil respiration and its components in a coppice oak forest in Central Italy. Global Change Biol. 8 (9), 851-866.

Richardson, A.D., et al., 2009. Influence of Spring Phenology on Seasonal and Annual Carbon Balance in Two Contrasting. New England Forests.

Richardson, A.D., et al., 2010. Influence of spring and autumn phenological transitions on forest ecosystem productivity. Phil. Trans. R. Soc. B : Biol. Sci. 365 (1555), 3227-3246.

Richardson, A.D., et al., 2013. Climate change, phenology, and phenological control of vegetation feedbacks to the climate system. Agric. Forest Meteorol. 169, 156-173.

Roser, C., et al., 2002. Net CO2 exchange rates in three different successional stages of the "Dark Taiga" of central Siberia. Tellus B 54 (5), 642-654.

Rosseel, Y., 2012. Lavaan: an R package for structural equation modeling. J. Stat. Softw. 48 (2), 1-36.

Sacks, W.J., Schimel, D.S., Monson, R.K., 2007. Coupling between carbon cycling and climate in a high-elevation, subalpine forest: a model-data fusion analysis. Oecologia 151 (1), 54-68.

Schmid, H.P., Grimmond, C.S.B., Cropley, F., Offerle, B., Su, H.B., 2000. Measurements of $\mathrm{CO} 2$ and energy fluxes over a mixed hardwood forest in the mid-western United States. Agric. Forest Meteorol. 103 (4), 357-374.

Schulze, E.D., Fuchs, M.I., Fuchs, M., 1977. Spacial distribution of photosynthetic capacity and performance in a mountain spruce forest of northern Germany. 1. Biomass distribution and daily co2 uptake in different crown layers. Oecologia 29 (1), 43-61.

Schumacker, R.E., Lomax, R.G., 2004. A Beginner's Guide to Structural Equation Modeling. Psychology Press.

Schwartz, M.D., Ahas, R., Aasa, A., 2006. Onset of spring starting earlier across the Northern Hemisphere. Global Change Biol. 12 (2), 343-351.

Stockli, R., Vidale, P.L., 2004. European plant phenology and climate as seen in a 20-year AVHRR land-surface parameter dataset. Int. J. Remote Sens. 25 (17), 3303-3330.

Suni, T., et al., 2003. Long-term measurements of surface fluxes above a Scots pine forest in Hyytiala, southern Finland, 1996-2001. Boreal Environ. Res. 8 (4), 287-301.

Tucker, C.J., et al., 2001. Higher northern latitude normalized difference vegetation index and growing season trends from 1982 to 1999. Int. J. Biometeorol. 45 (4), 184-190.

Urbanski, S., et al., 2007. Factors controlling CO2 exchange on timescales from hourly to decadal at Harvard Forest. J. Geophys. Res.-Biogeo 112 (G2).

Van Dijk, A.I.J.M., Dolman, A.J., 2004. Estimates of CO2 uptake and release among European forests based on eddy covariance data. Global Change Biol. 10 (9), 1445-1459.

Vargas, R., et al., 2010. Ecosystem CO2 fluxes of arbuscular and ectomycorrhizal dominated vegetation types are differentially influenced by precipitation and temperature. New Phytol. 185 (1), 226-236.

Wang, W., et al., 2013. Variations in atmospheric CO2 growth rates coupled with tropical temperature. Proc. Natl. Acad. Sci. U. S. A. 110 (32), 13061-13066.

Wang, X., et al., 2014. A two-fold increase of carbon cycle sensitivity to tropical temperature variations. Nature 506 (7487), 212-215.

White, M.A., Nemani, R.R., 2003. Canopy duration has little influence on annual carbon storage in the deciduous broad leaf forest. Global Change Biol. 9 (7), 967-972.

Wohlfahrt, G., et al., 2008. Seasonal and inter-annual variability of the net ecosystem CO2 exchange of a temperate mountain grassland: effects of weather and management. J. Geophys. Res-Atmos. 113 (D8).

Wu, C., Chen, J.M., 2013. Deriving a new phenological indicator of interannual net carbon exchange in contrasting boreal deciduous and evergreen forests. Ecol. Indic. 24, 113-119.

Wu, C., et al., 2013. Interannual variability of net ecosystem productivity in forests is explained by carbon flux phenology in autumn. Global Ecol. Biogeogr. 22 (8), 994-1006.

Xia, J., et al., 2015. Joint control of terrestrial gross primary productivity by plant phenology and physiology. Proc. Natl. Acad. Sci. 112 (9), 2788-2793.

Xu, L.K., Baldocchi, D.D., 2004. Seasonal variation in carbon dioxide exchange over a Mediterranean annual grassland in California. Agric. Forest Meteorol. 123 (1-2), 79-96.

Zeng, N., Mariotti, A., Wetzel, P., 2005. Terrestrial mechanisms of interannual CO2 variability. Global Biogeochem. Cycles 19 (1).

Zhou, S., et al., 2016. Explaining inter-annual variability of gross primary productivity from plant phenology and physiology. Agric. Forest Meteorol. 226-227, 246-256. 